\title{
DEL CRÉDITO TRADICIONAL COLONIAL AL CRÉDITO MODERNO. PERSPECTIVAS Y FUENTES. CHILE: EL CRÉDITO EN LA PERIFERIA
}

\author{
Eduardo Cavieres F.*
}

Q ntre las publicaciones más recientes sobre historia económica del periodo colonial americano, destaca la de Antonio Miguel Bernal, cuyo nudo central, tal como lo indica el nombre de la obra, es el problema de la financiación de la Carrera de Indias. El autor explica la importancia y los fundamentos del tema y señala cómo, desde comienzos de la presencia hispana en América, la iniciativa privada, al instrumentalizar y financiar las operaciones económicas, lo hizo bajo supuestos evolucionados del capitalismo mercantil y puso en juego, entre otros elementos, los instrumentos de crédito más idóneos con objeto de maximizar beneficios: "la esencia que vivificó la negociación mercantil con las Indias sería, ante todo, el crédito [...] vender al fiado y a largos plazos era consustancial al comercio colonial". De este modo, crédito y dinero estaban unidos en el comercio en cuanto las remesas americanas marcaban los ritmos de la circulación monetaria europea en los siglos XVI y XVII y mundial durante el siglo XVIII. ${ }^{1}$

Ésta no es una valoración única ni menos aún la visión más tradicional existente respecto al crédito colonial. Por el contrario, como es sabido, la idea de una economía limitada y de mercados poco desarrollados en los cuales el crédito no

*Profesor en la Universidad Católica de Valparaíso y Universidad de Chile, Santiago. Trabajo inserto en Proyecto FONDECYT, $\mathrm{N}^{\circ} 195.0879$.

${ }^{1}$ Antonio-Miguel Bernal, La financiación de la Carrera de Indias 1492-1824. Dinero y crédito en el comercio colonial español con América, Sevilla, 1992, pp. 19 y 23 en el prólogo. 
tuvo mayor significación, ha sido bastante generalizada e, incluso, hay todavia quienes sostienen que algunas de sus formas, especialmente la del censo, considerado como carga y gravamen, fue obstáculo económico más que factor dinamizador. Además, esta situación está muy relacionada con la hipótesis general, aún existente, referida a explicar el que se suponia exiguo espíritu emprendedor de la península y sus colonias según los frenos morales y eclesiásticos impuestos sobre el interés y la usura, hipótesis, por lo demás, seriamente cuestionable por los hechos y sus evidencias.

Indudablemente, un estudio más completo requiere, a lo menos, del análisis de las fuentes jurídicas que desde los últimos tiempos medievales iluminaron el pensamiento y la acción hispana sobre el particular. A ello debe agregarse el estudio de los pensadores y compiladores contemporáneos $\mathrm{e}$, indudablemente, el análisis particular de las Órdenes y Reales Cédulas emanadas en el tiempo y de sus circunstancias. Respecto a los préstamos y cambios marítimos, las contratas a la gruesa o préstamo a riesgo marítimo, el mismo Bernal nos presenta una muy clara sintesis del desarrollo de estos instrumentos económicos, de las fuentes apropiadas para su estudio y del "estado de la cuestión" actual. ${ }^{2}$

En las actividades mercantiles propiamente tales, desde la península y en la península, el sistema crediticio fue siempre una realidad en expansión. Considerando sólo la creciente influencia vasca en Sevilla y Cádiz y su participación en la banca sevillana prácticamente desaparecida a comienzos del siglo XVII, los cuatro importantes y únicos compradores de oro y plata, vascos que eran a su vez mercaderes, industriales, navieros y auténticos banqueros, a través de los protocolos notariales de la segunda mitad de dicho siglo dejaron testimonios de "la multitud de operaciones de préstamo que realizaban". 3

Para la Carrera de Indias, uno de los estudios de García-Baquero es también importante en la presentación del contexto que se requiere para realizar un buen análisis de la materia que nos preocupa. Focaliza su atención en el crédito llamándole "el mecanismo predilecto para la financiación del comercio indiano", especificamente en el cambio maritimo o préstamo a riesgo, difundido en todos los ámbitos comerciales y a tal modo que el siempre citado Tomás de Mercado lo veia como un monstruo de cambios, sin figura ni apariencia, una mixtura de cambio, por otra de usura. ${ }^{4}$ Por su parte, las Ordenanzas de Bilbao le definían como el dar y tomar dinero, por ciertos intereses o premios, sobre cascos de navíos, aparejos, bastimentos, armamentos y aprestos para un viaje; o sobre mercaderías, 0 efectos cargados en ellos, y que llegando a destino quedaban libres de riesgo los

${ }^{2}$ Ibid., cap. II: “Cambios y riesgos en España", pp. 57-86.

${ }^{3}$ Lutgardo García Fuentes, Sevilla, los vascos y América, Bilbao, 1991, espec. pp. 34-36.

${ }^{4}$ Tomás de Mercado, Summa de tratos y contratos, Sevilla 1569, Nicolás Sánchez Albornoz, Madrid, 1977 
dadores de las cantidades para practicar la cobranza de sus principales y sus respectivos premios en los tiempos pactados. ${ }^{5}$

El mismo García-Baquero aclara cómo el seguro marítimo y el préstamo a riesgo mostraban diferencias. En tanto el primero tenía por finalidad principal cubrir un riesgo, el segundo era susceptible de ser negociado y de producir beneficios comerciales, convirtiéndose en un simple préstamo comercial a pagar con sus intereses correspondientes, salvo que hubiese siniestro. Por ello también, sus operaciones crediticias más usuales se desarrollaron en torno a las mercancías o sobre el navío que las transportaba. Igualmente importante para nuestro propio análisis es el hecho de que, a pesar que entre sus protagonistas principales estaban naturalmente el acreedor y el deudor, bajo este último concepto se consideraba un enorme espectro que incluía desde marineros hasta maestres y dueños de navíos y una gama intermedia de comerciantes, encomenderos y funcionarios que navegaban también gracias al crédito. ${ }^{6}$

Aunque la legislación existente no fuese lo suficientemente clara con respecto al monto o porcentaje de los intereses a pagar, haciéndolos algo flexibles según el lugar de destino, la duración del viaje, y la mayor o menor seguridad en la ruta, los términos temporales del contrato eran un principio general que comenzaba a regir desde el día, punto y hora en que el navío dejaba el puerto hasta transcurridas 24 horas de su arribo al puerto de destino. Esta situación, planteada para el caso de la Carrera de Indias propiamente tal, como lo veremos oportunamente, fue también muy válida y usual en los circuitos comerciales más pequeños que conformaban las estructuras menores del gran comercio colonial.

Precisamente, al detenernos en el espacio colonial del virreynato del Perú, es obvio que, salvo las diferencias regionales, no estamos descubriendo situaciones desconocidas en las otras áreas de los dominios americanos. Lo que buscamos es sólo el focalizar nuestro análisis desde una situación global como la ya descrita, pasando por un espacio intermedio, para detenernos finalmente en una economía particular. Conviene recordar brevemente el funcionamiento de la economía colonial utilizando, por ejemplo, conceptos e imágenes braudelianas como los juegos del intercambio en que se describe todo el dinamismo de las relaciones económicas: conjunción de oferta y demanda, producción y circulación de mercaderías, tráfico y movimiento de productos y hombres, participaciones directas y visibles, pero también vinculaciones invisibles, especialmente cuando ellas se refieren al crédito.

La mayoría de los estudios realizados respecto a las relaciones Sevilla/CádizCallao se orientan básicamente a constataciones concretas de este juego de los

\footnotetext{
SAntonio Garcia-Baquero, La Carrera de Indias: suma de la contratación y océano de negocios, Sevilla, 1992. En pág. 254 cita a Mercado y las Ordenanzas.

${ }^{6}$ Ibid., pp. 256-258.
} 
intercambios: sistemas de flotas o navíos de permiso; rutas del Istmo o del Cabo de Hornos a partir de la década de 1740; convergencia de los grandes comerciantes limeños a las ferias del siglo XVII o dirección de sus negocios y redes de influencia desde sus propios asentamientos en Lima. Por supuesto, mayores aproximaciones a los tipos de mercaderías y sus volúmenes: ¿qué viene desde el Atlántico?, ¿qué se lleva hacia España? Cuantificaciones de lo más preciado: los retornos en metales preciosos. Obviamente todo es importante, pero estos retornos no son solamente producción de metales, sino también intercambio de mercaderías e igualmente pagos, utilidades e intereses. Sobre esto último sabemos menos, pero no de poca significación.

Como ya lo hemos señalado, la financiación de la Carrera de Indias estuvo en directa relación con la expansión y generalización de las formas crediticias. Utilizando la documentación referente al valor de las mercancías embarcadas y la propiedad de los caudales que se encuentra en el Fondo de Contratación (Archivo General de Indias), García Fuentes ha observado el significativo peso alcanzado en la primera mitad del siglo XVII por los hombres de negocios de Lima, los peruleros, que "enviaban grandes sumas de dinero a España, a México, y a través del galeón de Manila, al Extremo Oriente". Al mismo tiempo, ya que Sevilla era destino o plaza obligada de un elevado porcentaje de esos y otros caudales, dicha situación exigía a los grandes cargadores sevillanos a comprometerse en funciones de factoraje, comisión o de intermediación entre las grandes casas indianas y los mayoristas allí establecidos. Debe recordarse que, con el tiempo, en 1735 se llegó a prohibir el envío de dinero americano a España para ser empleado en la adquisición directa de mercaderías y que se debió esperar hasta 1749 para la rectificación de dichas disposiciones. ${ }^{7}$ Lo anterior es una buena señal de que, en muchos casos, la venta a crédito es más lucrativa y crea más influencias que la venta directa y al contado.

Más directamente relacionado con el desarrollo del crédito propiamente tal, el ya mencionado Bernal, estudiando las escrituras de riesgos, cuya obligatoriedad de registro en la Contaduría del Consulado de Cádiz se reactualizó en 1760, permite apreciar la expansión del crédito y la pertinencia de éste en la descripción de la vida económica de los diferentes centros americanos. Entre 1760 y 1788 , de 30483 escrituras de riesgos documentadas, $21.94 \%$ tenía como puerto de destino a Callao-Lima o el Mar del Sur, en donde dicho eje también participaba activamente. En términos de los valores allí representados, $29.30 \%$ correspondía al mismo centro mercantil. Podemos distinguir tam-

\footnotetext{
${ }^{7}$ Lutgardo Garcia Fuentes, "Cambios en la demanda y oligopolio de la oferta: un nuevo enfoque de las relaciones comerciales entre España y las Indias, 1580-1630", Hespérides. Anuario de Investigaciones, Granada, 1993, vol. 1, especialmente pp. 550-559.
} 
bién los acreedores más importantes reconocibles en sus vinculaciones con el Sur americano. Babil Uriz S., Cinco Gremios, Fernández Somera Hnos., Izquierdo N., Landaburu M., Martínez Junquera M., Rivero M. e Hijos, Ustariz y Cía., son nombres siempre presentes en los registros de los barcos que se movían entre Cádiz y Callao. En las series de Bernal, Landaburu es acreedor de $8.18 \%$ del total de las escrituras de riesgo del periodo, los Cinco Gremios del $7.07 \%$, Ustáriz sólo del $2.83 \%$. Evidentemente, sus intereses eran mucho más amplios. ${ }^{8}$

Deteniéndonos ya en la segunda mitad del siglo XVIIl, podemos centrar nuestra atención en Lima. Con menos estudios que para el caso mexicano, se sabe que el auge del comercio peruano de fines del siglo XVI hasta mediados del siguiente (periodo al cual ya nos hemos referido), estuvo ligado al crecimiento de la producción minera y a la incidencia de ésta en todos las estructuraciones económicas regionales. En ese contexto, e impulsados por los crecidos intereses de la plata, el número de compromisos documentados entre prestamistas y comerciantes o cargadores fue multiplicándose, y para ello la ya conocida escritura de riesgo de mar fue también base del crédito comercial. Después de 1640, con la caída de la producción minera, el capital destinado hacia el gran comercio se reorientó y afectó positivamente a las redes crediticias locales. ${ }^{9}$

Por redes crediticias locales podemos entender una muy variada y compleja situación. Su significado se relaciona directamente con la estructuración de mercados que van desde microespacios hasta espacios regionales y que, además de los factores políticos y administrativos que les encuadran, se van determinando por las vinculaciones de poder existentes en que el control de la circulación de mercaderías y del crédito surge como fundamental. Los tipos y alcances de la presencia limeña en sus periferias inmediatas son temática importante de la historiografia colonial peruana y sus contenidos materia bien conocida. Desde el punto de vista del crédito, son sugerentes los estudios que consideran no sólo la actividad de comerciantes y mineros, sino también el papel jugado por la Iglesia (censos y capellanías) y por los corregidores a través de los repartos forzosos de mercaderías que no sólo significaron la existencia de mercados compulsivos sino también violentas formas involuntarias de endeudamiento. En el estudio de redes mercantiles que traspasaron las difusas fronteras de la economia monetaria y la economía natural (habilitaciones y

\footnotetext{
${ }^{8}$ Antonio-Miguel Bernal, "Riesgos y cambios en la Carrera de Indias, 1760-1788", en Carlos III y la Ilustración, Madrid, 1989, t.II, pp.289-313, Los datos han sido calculados a partir de los cuadros 2 y 3 A, pp. 304-305 y 308-309, respectivamente.

${ }^{9}$ Véase, Alfonso W. Quiroz, Deudas olvidadas. Instrumentos de crédito en la economia colonial peruana, 1750-1820, Lima-Perú, 1993.
} 
préstamos; deudas y trueques), los trabajos de Flores Galindo son altamente ilustrativos. $^{10}$

A través del entrecruzamiento de redes locales y la superación de los espacios intermedios, la conformación de mercados regionales estuvo íntimamente influida por los alcances del sistema crediticio. Desde las formas asumidas por el crédito intercontinental que hemos visto anteriormente, pasando por las dependencias directas e indirectas del comercio colonial, se fue extendiendo un paraguas común que dejó bajo sí todo aquello posible de mercantilizar. A mediados del siglo XVIII, aunque subsistieran intercambios tradicionales, la economía americana había alcanzado un fuerte grado de mercantilización.

Para entonces, y en ese contexto, las vinculaciones mercantiles y crediticias de Lima con Santiago estaban perfectamente maduras a través de un sistema que funcionaba con todo el racionalismo económico de la época. El estudio de sus mercados, productos en circulación y comerciantes comprometidos, incluye el financiamiento que hizo posible ese intercambio $\mathrm{y}$, aunque no siempre las fuentes nos entreguen indicios directos de ello, sus montos y carácter se pueden perfectamente deducir de las vinculaciones, influencias y contratos producidos entre los sectores económicos participantes.

Para el conocimiento del movimiento marítimo entre Callao y Valparaíso, las partidas de registro de los barcos son esenciales. Las tenemos y conocemos no sólo para dicho circuito (documentaciones en Capitanía General, Real Audiencia y Contaduría Mayor en el Archivo Nacional de Santiago de Chile), sino además para el correspondiente a Callao-Cádiz y viceversa en las cuales igualmente se mencionan comerciantes santiaguinos (fondos Indiferente General, Contratación y Audiencia de Lima en el Archivo General de Indias, Sevilla).

Específicamente, en el movimiento Callao-Valparaíso, además del registro de las mercaderías, aparece un número significativo de compromisos referidos a escrituras de riesgo de mar en que los maestres de barcos, representando a comerciantes involucrados en los negocios o a los dueños de los mismos navíos, adquirían compromisos monetarios con objeto de comprar parte o la totalidad del cargamento a fletar. La figura jurídica utilizada era lógicamente similar a la forma descrita más arriba para España.

Para ilustrar lo anterior, bastará con un par de ejemplos documentados en el año 1768. En los registros de salida del San Joseph (Valparaíso a Callao), Santiago Joseph de Moya, en nombre y como apoderado de don Juan Ignacio Hernández, dueño de dicha fragata, escrituraba la recepción de 2385 pesos de parte de don

\footnotetext{
${ }^{10}$ Entre ellos, "Aristocracia en vilo. Los mercaderes de Lima en el siglo XVII", en Nils Jacobsen y HansJargen Puhle (comps.), The economies of Mexico and Peru during the late colonial period, 1760-1810, Colloquium Verlag, Berlin, 1986, pp. 252-280.
} 
Diego de Armida, "incluso su premio de riesgo de mar", para los últimos avíos y rancho de la nave, a pagar en Lima a don Melchor Jiménez a 40 días a contar de las 48 horas siguientes a su arribo al puerto de destino. Por su parte, en los registros del Phenix, de cuenta, costa y riesgo de los señores Manuel Sánchez del Cueto y Joseph Montuoro, el comerciante santiaguino Pedro Fernández Palazuelos remitía 5900 pesos pertenecientes a una escritura por la misma cantidad, "a riesgo de mar", verificada en la fragata El Águila y otorgada en Cádiz el 21 de enero de ese año. En Lima se ordenaba entregar el dinero a Juan Antonio Bustamante para que éste lo remitiera a Cádiz a don Manuel Díaz Saravia. ${ }^{1}$

En general, estos préstamos marítimos, unidos al endeudamiento mercantil propiamente dicho, originó un movimiento de capitales Santiago-Callao relativamente importante. A partir del análisis específico del comportamiento del mercado, el tema lo hemos desarrollado más ampliamente en otro trabajo, pero es útil señalar los principales remitentes y receptores de dichos dineros. Domingo Valdés, el representante de Ustáriz Hermanos, Miguel de Cotapos, Matheo de Toro (conde de la Conquista), el conde de Quinta Alegre, Juan Saburgo, canalizaban alrededor de 35\% del total de remesas; el conde de San Javier, Ustáriz Hermanos, Felipe Zaldivar, Francisco Rodriguez, Juan Antonio Quevedo y Francisco Lombera, alrededor de $40 \%$ de lo recibido en Callao. Para nuestro análisis interesa especialmente retener los nombres de los comerciantes santiaguinos pero, además, cabe agregar que el conde de San Javier era el segundo hombre de negocio en importancia que manejaba el tráfico del trigo, y la casa de Ustáriz Hermanos la más comprometida en el del cobre, las dos principales exportaciones chilenas al Callao y Cádiz (via Callao), respectivamente. ${ }^{12}$

Si los grandes comerciantes limeños combinaban sus operaciones mercantiles comprometiéndose en circuitos externos y organizando sus propias redes de poder internas, de igual manera actuaban los comerciantes santiaguinos. Hablamos en particular del crédito mercantil y, en este caso, quizás la fuente más importante para su análisis corresponde a las escrituras de obligaciones registradas en los archivos de escribanos (notarios).

En nuestro caso, hemos utilizado Escribanos de Santiago, vols. 742 a 803, correspondientes a los años 1759 a 1798 . Alli hemos revisado un total de 906 escrituras de obligaciones que se registraron con indicación de los valores de los compromisos asumidos, nivel del interés pactado, nombre de las personas involucradas y propósito del préstamo. Se trata de crédito mercantil y, por ello, no es sorprendente que gran parte de los préstamos concedidos fuesen más bien traspaso de mercaderías.

\footnotetext{
${ }^{11}$ Capitania General, vol. 359, fjs. 365-378 y 442-458.

${ }^{12}$ Eduardo Cavieres, El comercio chileno en la economia-mundo colonial, Valparaiso, 1996, especialmente cap. 3.
} 
CUADRO 1. ESCRITURAS DE OBLIGACIONES, SANTIAGO 1759-1798

\begin{tabular}{lrrrrrr}
\hline Periodo & 1 & 2 & 3 & 4 & 5 & 6 \\
& & & & & & \\
$1759-1766$ & 103 & 162775 & 14 & 71656 & 13.59 & 44.02 \\
$1767-1774$ & 181 & 433918 & 36 & 238446 & 19.88 & 54.95 \\
$1775-1782$ & 389 & 891004 & 84 & 466695 & 21.59 & 52.37 \\
$1783-1790$ & 150 & 468439 & 36 & 250726 & 24.00 & 53.52 \\
$1791-1798$ & 83 & 238308 & 12 & 108923 & 14.45 & 45.70 \\
& 906 & 2194444 & 182 & 1136446 & &
\end{tabular}

1. Número de escrituras registradas.

2. Valor total de las escrituras del periodo.

3. Número de escrituras de valor superior a 3000 pesos.

4. Valor total de las escrituras de valor superior a 3000 pesos.

5. Porcentaje de 3 respecto a 1 .

6. Porcentaje de 4 respecto a 2.

FuENTES: Escribanos de Santiago, vols. 742 a 803.

Revisando solamente las obligaciones por valor superior a los 3000 pesos, podemos individualizar a quienes controlaban el crédito interno del centro mercantil santiaguino y sus propias periferias. De este grupo de préstamos, en la nómina señalamos el porcentaje de participación de los principales comerciantes con respecto al total de los préstamos de cada periodo.

CUADRO 2. COMERCIANTES MÁS IMPORTANTES Y SU PARTICIPACIÓN

PORCENTUAL EN EL CRÉDITO INTERNO DIRIGIDO

DESDE SANTIAGO, 1759-1798

\begin{tabular}{|c|c|c|c|c|c|}
\hline & $1759-66$ & $1767-74$ & $1775-82$ & $1783-87$ & $1791-98$ \\
\hline Diego Muñoz & 30.12 & & & & \\
\hline Conde Qta. Alegre & & 20.84 & 6.27 & & \\
\hline Matheo Toro & & 22.69 & & & \\
\hline Domingo Valdés & & 11.31 & 4.49 & 7.16 & \\
\hline Antonio de la Lastra & & 6.54 & 11.57 & 13.81 & \\
\hline Marqués Villa Palma & & & 5.08 & & \\
\hline Joseph Ramirez & & & 3.67 & 7.66 & \\
\hline Domingo Díaz Salcedo & & & 4.27 & 4.20 & \\
\hline Fco. Xavier Toro & & & & & 46.38 \\
\hline
\end{tabular}

FuENTES: Escribanos de Santiago, vols. 742-803. 
Recordemos, en primer lugar, la lista de los principales remitentes de dinero a Callao indicados anteriormente. De los seis personajes que hemos señalado, acá se repiten Domingo Valdés, Matheo de Toro (conde de la Conquista) y el conde de Quinta Alegre. Por lo demás, el conde de la Conquista y los marqueses de Villa Palma y el de Quinta Alegre, junto con don Joseph Ramírez, figuraban entre los primeros siete grandes acaudalados de Santiago, en una nómina de 36 personas, confeccionada en 1790 por la misión científica de Alejandro Malaspina enviada por la corona de España a América. ${ }^{13}$

Podemos sacar algunas conclusiones generales. En primer lugar, del cuadro 1 se desprende la existencia de una contracción del crédito mercantil a partir de 1783, situación que podría explicarse por el fuerte aumento de la oferta de mercaderías europeas, saturación del mercado y consiguiente baja de precios al no haber correlación con la demanda. Además, es significativa la baja de intereses que comienza a generalizarse precisamente desde 1779-1789 pasando, en promedio, de 8 a 5 por ciento.

En general, el periodo 1767 a 1787 parece ser el de mayor expansión económica y crediticia de la época. Es también el periodo en que los hombres de mayor influencia económica y social de la segunda mitad del siglo XVIII alcanzaron su mayor significación. En los extremos, Diego Muñoz (1759-1766) fue un experimentado hombre de negocios, representante de comerciantes peruano y distribuidor de mercaderías en los mercados locales internos. Por otra parte, Francisco Xavier Toro (1791-1798) manejaba fundamentalmente crédito minero, representando así la fuerte tendencia de cambio de la economía chilena desde la producción y exportación cerealística predominante en ese siglo hacia la producción y exportación cruprifera que, lejos, caracterizaría gran parte del siglo XIX.

Los hombres más influyentes de los periodos intermedios, 1767 a 1790 , comenzaban también su repliege. A pesar de que hemos minimizado sus influencias crediticias al analizar sólo escrituras registradas en Santiago y considerar sólo aquellas superiores al monto de 3000 pesos, es evidente que la transición del Siglo de las Luces europeo al de la emergencia de las repúblicas americanas, no fue sólo de carácter político o económico. Fue algo mucho más complejo de lo cual el crédito y sus implicaciones es sólo una evidencia de muchas otras alteraciones.

En efecto, después de 1780 fueron varios los factores que influyeron en la gran coyuntura de las primeras décadas del siglo siguiente. En términos generales, las reformas económicas y administrativas, rodeadas de sus imágenes ilustradas, tuvieron efectos insospechados y muy lejanos a lo que pensaron

\footnotetext{
${ }^{13}$ Juan Ricardo Couyomdjian, "Los magnates chilenos del s. XVII", Revista Chilena de Historia y Geografia, núm. 136, Santiago, 1968, pp. 315-322.
} 
quienes las gestaron e impulsaron. En têrminos particulares, la liberalización del comercio y la pérdida de la Audiencia de Charcas con la creación del virreinato de la Plata, creó un sentido malestar y muy fuertes sacudidas al comercio de Lima.

Posiblemente, una de las respuestas del sector dirigente de la Ciudad de los Reyes pudo ser el reforzamiento de sus presiones sobre Santiago, especialmente en momentos, como se ha visto, en que la generación mercantil aristocrática chilena más influyente del siglo, reorientaba sus inquietudes e intereses y dejaba su lugar a una nueva generación y a los nuevos tiempos. Lo que sí es seguro es que las reorganizaciones y reestructuraciones de los mercados tradicionales y de las posiciones de quienes actuaban en ellos, eran un proceso en marcha.

La reestructuración de mercados y la reinserciǒn de éstos en nuevos espacios económicos afectó también el carácter del crédito y de su función económica. Para el siglo XVII, el crédito fue fundamentalmente mercantil $y$, por ende, posibilitó la ampliación de los mercados y de la circulación de mercaderías. Por las diferencias en los grados de complejidad de las operaciones de financiamiento y por los distintos niveles de participación de quienes estaban involucrados en él, es dificil hablar únicamente de un crédito tradicional, pero su mayor relación con las actividades mercantiles aparece bastante clara. No obstante, al crédito mercantil deben agregarse el crédito eclesiástico y el crédito minero.

Sobre el crédito eclesiástico (censos y capellanias), mucho se ha dicho y escrito. En un sugerente artículo sobre el papel de la Iglesia en la economía hispanoamericana de los siglos XVIII y XIX y las dificultades conceptuales existentes para definir con precisión los alcances de censos, obras pías, aniversarios, memorias, capellanías y depósitos, Bauer escribió una buena síntesis de tan compleja temática y reforzó la idea de que las fuertes diferencias regionales incidieron no sólo en la existencia de Iglesias muy ricas, sino también en las formas en que éstas participaron en los mercados crediticios locales.

El banco del periodo colonial: institución congeladora de capitales o, por el contrario, derivación de sus riquezas a través de préstamos a terceros; relación simbiótica entre la Iglesia y dicho grupo social, su cliente predilecto, siguen siendo centro de debates y concuerda esencialmente con el modelo surgido a propósito de los estudios sobre México. ${ }^{14}$

Las diferencias regionales son muy amplias. En la región de La Serena, una de las tres regiones económicas del Chile colonial, la Iglesia cumplía también un papel social al orientar sus préstamos en valores reducidos, pero en

\footnotetext{
${ }^{14}$ Arnold Bauer, "La Iglesia en la economía hispanoamericana: los censos y depósitos en los siglos XVIII y XIX", Cuadernos de Humanidades, núm. 4, serie 2, Universidad de Santiago de Chile, 1989, pp. 1-39.
} 
gran cantidad, a pequeños propietarios con el objeto de que pudiesen mantener su producción. ${ }^{15}$

La otra forma de crédito colonial, la de carácter minero, es la conocida habilitación, que puso en permanente relación a los sectores comercial, como financista, y minero, como productor. Con diversas modalidades en los principales centros mineros de México y Perú, en Chile el sistema fue perfilándose y creciendo a partir de la segunda mitad del siglo XVIII en torno a los yacimientos de cobre en forma semejante a los adelantos que se hacían a los agricultores a cuenta de las compras en verde o de los principales volúmenes de la producción. Sin embargo, a lo largo del siglo XIX llegará a ser el centro del sistema crediticio y motor principal de la economía nacional.

Precisamente, en la evolución de este crédito minero se podría observar uno de los aspectos más relevantes de la transición del crédito tradicional al que asume una mayor modernidad. Se trata fundamentalmente del paso del crédito mercantil al crédito para la producción. No es que el crédito mercantil desaparezca, tampoco de que no siga ligado a la producción. Lo que sucede es que, a partir del siglo XIX, la financiación de la actividad cuprífera chilena estuvo asociada a los comerciantes británicos que si bien es cierto no aportaron capitales frescos (más bien produjeron capitales a través del comercio), impusieron una actitud y una presión de tal significación sobre el mercado y el sector productivo local, que obligaron a pensar y a actuar en el mundo de los negocios con una racionalidad diferente.

Así como se reacomodaron las vinculaciones personales entre comerciantes y productores, así también se redimensionaron las redes y los niveles del crédito. Si bien es cierto que las estructuras tradicionales de base no desaparecieron, sus formas y modalidades siguieron adecuándose a las nuevas circunstancias. El problema de la financiación, el problema del crédito en sí mismo, seguía plenamente vigente en la conformación de nuevas dependencias.

\footnotetext{
${ }^{15}$ Eduardo Cavieres, La Serena en el s. XVIII. Las dimensiones del poder local en una sociedad tradicional, Valparaiso, 1993, cap. 3: "La Iglesia y el crédito colonial. Capellanias, censos y participación en la vida económica regional".
} 